\title{
Use of e-Health by Healthcare Professionals vs. non-Healthcare Professionals
}

\author{
Rolf WYNN ${ }^{\mathrm{a}, 1}$, Sunday O. OYEYEMI ${ }^{\mathrm{a}}$, Luis MARCO-RUIZ ${ }^{\mathrm{b}}$, \\ Andrius BUDRIONIS ${ }^{\mathrm{b}}$, Kassaye Yitbarek YIGZAW ${ }^{\mathrm{b}}$ and Johan G. BELLIKA ${ }^{\mathrm{a}, \mathrm{b}}$ \\ a UiT - The Arctic University of Norway, Tromsø, Norway \\ ${ }^{\mathrm{b}}$ Norwegian Centre for E-health Research, University Hospital of North Norway, \\ Tromsø, Norway
}

\begin{abstract}
The role of e-health is increasing worldwide. We surveyed the use of ehealth in a large-scale population-based study, involving a representative sample of the Norwegian population aged above 40 years. Two-thirds of the health professionals had used search engines, apps, social media or video services for health purposes - while this was the case for approximately half of the non-health professionals.
\end{abstract}

Keywords. E-health, health professionals, population-based survey

\section{Introduction}

The use of e-health is increasing. The most frequently used type of e-health is obtaining information about health and illness by using web search engines such as Google. However, other services are gaining importance as sources of health information and other health-related content, including health apps, social media and video services such as YouTube [1-3]. Health professionals may be early adopters of e-health and may through their interaction with patients play a positive role in increasing patients' use of such services [4]. Moreover, health professionals may play a central role in developing and improving e-health services. We therefore wanted to examine how health professionals compare to non-health professionals in their own use of e-health services.

\section{Methods}

The Tromsø 7 study involved a sample of citizens of Tromsø, Norway aged above 40. Participants completed questionnaires and participated in physical examinations and lab tests. Data pertaining to profession and e-health use were analyzed for the present study, focusing on frequencies and between-group statistics. More details about the study and other results have been published elsewhere $[1,5,6]$.

\footnotetext{
${ }^{1}$ Corresponding author, Rolf Wynn, Department of Clinical Medicine, UiT The Arctic University of Tromsø, N-9038 Tromsø, Norway. Email: rolf.wynn@gmail.com.
} 


\section{Results}

In our sample of 1381 self-identified health professionals and 6089 non-health professionals, $66.5 \%$ of the health workers and $51.2 \%$ of the non-health workers had used search engines, apps, social media and video services for health purposes (defined as having used services for information and advice on health and disease issues) in the last year (Table 1). The difference in the proportion of use in the two groups was statistically significant $(15.3 \%, 95 \%$ CI $12.47 \%-18.04 \%, \mathrm{p}<0.0001)$.

Table 1. Frequency of use of e-health among healthcare professionals and non-healthcare professionals

\begin{tabular}{ccc}
\hline Frequency of use & Healthcare professional (\%) & $\begin{array}{c}\text { Non-healthcare professional } \\
(\%)\end{array}$ \\
\hline Often & $167(12.1)$ & $354(5.8)$ \\
A few times & $641(46.4)$ & $2234(36.7)$ \\
Once & $111(8.0)$ & $530(8.7)$ \\
Never & $462(33.5)$ & $2971(48.8)$ \\
Total & $1381(100)$ & $6089(100)$ \\
\hline
\end{tabular}

\section{Discussion and Conclusions}

We found a statistically significant higher use of e-health services in the group of health professionals. This is not surprising considering that this group consists of many highly qualified people with at least a bachelor-level education. Prior studies [1] have found that educational level is an important predictor for e-health use. Moreover, health professionals may also use e-health for instance, to update themselves professionally or to find information for their patients. Many health professionals see e-health as beneficial to healthcare [7]. This study supports the idea that health professionals have a relatively high use of e-health and might be involved to a larger extent in the development and propagation of e-health within the health services.

\section{References}

[1] Wynn R, Oyeyemi SO, Budrionis A, Marco-Ruiz L, Yigzaw KY, Bellika JG. Electronic Health Use in a Representative Sample of 18,497 Respondents in Norway (The Seventh Tromsø Study - Part 1): Population-Based Questionnaire Study. JMIR Med Inform. 2020 Mar 5;8(3):e13106.

[2] Wynn R, Gabarron E, Johnsen JK, Traver V. Special Issue on E-Health Services. Int J Environ Res Public Health. 2020 Apr 22;17(8):2885.

[3] Wynn R. E-Health in Norway Before and During the Initial Phase of the Covid-19 Pandemic. Stud Health Technol Inform. 2020 Jun 26;272:9-12.

[4] Wynn R. Provider-patient interaction. Oslo: Høyskoleforlaget; 1998.

[5] Marco-Ruiz L, et al. Impact of Illness on Electronic Health Use (The Seventh Tromsø Study - Part 2): Population-Based Questionnaire Study. J Med Internet Res. 2020 Mar 5;22(3):e13116.

[6] Budrionis A, et al. G. Impact of the Use of Electronic Health Tools on the Psychological and Emotional Well-Being of Electronic Health Service Users (The Seventh Tromsø Study - Part 3): Population-Based Questionnaire Study. J Med Internet Res. 2020 Mar 5;22(3):e13118.

[7] Ruiz Morilla MD, Sans M, Casasa A, Giménez N. Implementing technology in healthcare: insights from physicians. BMC Med Inform Decis Mak. 2017 Jun 27;17(1):92. 